Sean A. Adams

\title{
Translating Texts: Contrasting Roman and Jewish Depictions of Literary Translations
}

The Greek and Roman worlds were polyglot, and although Greek and Latin were dominant in particular regions (East and West, respectively), this impression of linguist uniformity hardly hid a complex linguistic terrain. Indeed, across the Hellenistic and Roman Empires local languages continued to interact and shape the way that the dominant language users engaged with their conquered others. This political and cultural conquest resulted in the need to develop new methods of engagement and communication, both oral and written. Setting aside the act of oral translation, for which we have very little surviving evidence (although we know that it took place frequently), ${ }^{1}$ we find that discussion of text translation was not prominent. This is not to claim that translation was not a recognised element of ancient culture, but that it was so common that it did not warrant comment. ${ }^{2}$ Literary texts, however, were translated far less frequently and undertaken with a particular purpose(s) in mind.

In this chapter I will evaluate and contrast the ways that Roman and Jewish writers articulated their understanding of literary translation. This comparison is valuable as translators from both cultures engage with Greek literature, but do so from very different perspectives and positions. Accordingly, in order to have a fuller understanding of literary translation in antiquity, one must compare the different ways and purposes for translation that stem from both dominant and non-dominant peoples. It is this comparison that provides substantial insights into the nature of literary translation and highlights specific elements that are distinctive to particular groups. This chapter does not only look at specific literary translations and how the rendered text aligns with the original, although many of such texts will be consulted. Rather, the purpose of this investigation is also to evaluate how literary translation is discussed and presented by authors with the intentionality and purpose being of primary importance.

We will begin by briefly looking at some school texts that give insight into the training a student received with regard to translating texts. Following this we will assess the expressed purposes and functions of translation in the Hellenistic and Roman eras with a particular eye towards how Roman and Jewish authors engaged

\footnotetext{
1 On the important difference between 'interpreting' and 'translating', see Feeney (2016) 32-40. For an example of a misunderstanding between Romans and Greeks over the difference between fides and Tíotı, see Polybius, Hist. 20.9-10; Livy, Hist. 36.28. Cf. Caesar, Bell. gall. 1.19; Sallust, Bell. Jug. 109.4; Gellius, NA 6.14.7-9.

2 Janse (2002) 334; Rajak (2009) 138.
}

Sean A. Adams, University of Glasgow

https://doi.org/10.1515/9783110660982-010 
with Greek literary culture. I will outline some specific similarities and differences and argue that different motivations and expectations for translating works, especially with regard to power relations, are expressed in how select authors are said to have approached the task of translation. In particular, we find differences with regard to directionality, religiosity, fidelity, and chronology.

\section{Translation in Ancient Education}

In order to create successfully a new translation of a text from a source language to a target language the translator required a certain level of literary training in both languages and writing systems. ${ }^{3}$ Although it might not appear as such, learning the skill of translation was of fundamental importance within the school curriculum. In most cases, it was not rendering one language into another, but translating elements of ancient Homeric Greek into current vernacular. As widespread knowledge of Homeric (as well as Ionic and Attic) Greek receded into the increasingly distant past, there was a growing need for translational glosses to assist the challenged reader. This led not only to the rise of ancient Greek-to-Greek lexica, ${ }^{4}$ but also to the increased occurrence of glosses and paraphrases of difficult expressions, such as those found in D-scholia of Homer in Greek manuscripts. Accordingly, intralingual translation of Homer is a recognised element of literary education. ${ }^{5}$ For example, a first century scroll contains a school exercise in which the student paraphrased line by line the text of Iliad 2.617-70 (PSI XII 1276). ${ }^{6}$ Fragment 233 of Aristophanes shows a scene of oral instruction on Homeric words, providing an indication of how early this practice needed to start. Similarly, a more advanced exercise is found on a set of wooden tablets in which the student provided a rhetorical retelling of Il. 1.1-21. ${ }^{7}$ Such evidence reveals that intralingual translation was an integral part of schooling in the later Graeco-Roman world.

3 E.g., P.Fouad I 5 (4th-5th century CE) is a codex that presents Virgil, Aen. 3.444-468 with a Greek translation on the facing page. The hand, in both languages, is a practiced cursive. For the recent claim that a person competent in two languages would likely have good handwriting, see Mugridge (2016) 30.

There are a few mentions of ancient authors learning a second language later in life, but only with difficulty (E.g., Athenaeus, Deip. 3.127b; Lucian, Merc. cond. 23; Josephus, Ant. 20.263-64; Plutarch, Dem. 2.2). On the latter, see Mossman (1999). For the need for bilingualism in certain Egyptian archives, see Clarysse (2010).

4 For a larger discussion, see Tosi (2015) 1.622-36.

5 Morgan (1998) 110-19; Cribiore (2001) 194-97. Makrinos' judgment is apt: 'Homeric paraphrases are a long and continuous link in the history of the literary and linguistic tradition of the Homeric text'. Makrinos (2011) 2.626.

6 For a good example of paraphrasing in antiquity, see Plato, Resp. 393d-394a on the Iliad. For important differences, see Theon, Prog. 108-110 (Patillon); Quintilian, Inst. Or. 10.5.4-11.

7 Spooner (2002) 25-26. 
There is little evidence, however, that interlingual translation was part of the school curriculum in the Hellenistic and early Roman eras. This is not particularly surprising as the challenge of learning one language is difficult enough without adding a second. As far as ancient teachers were concerned, a youth would have only learned to read and write one language at a time: if one was exposed to Latin at home, than it would be best for that student to learn Greek at school. ${ }^{8}$ In Gramm. 1.1, Suetonius mentions that Livius and Ennius gave instruction in Rome, but did no more than translate (interpretabantur) Greek poets and give readings of what they had composed in Latin. ${ }^{9}$

Our best example of dual language use in the classroom comes from the Hermeneumata Pseudodositheana, anonymous bilingual instruction manuals that were used to help teach Latin to Greek speakers. Dating from the first century CE, the Hermeneumata contain two types of glossaries (alphabetic and thematic) of approximately 30,000 words and a series of dialogues which describe typical events in a student's day (cf. the glossaries by Ps.-Philoxenus and Ps.-Cyrillus). ${ }^{10}$ The Hermeneumata are not the only bilingual school texts to survive. ${ }^{11}$ Another helpful find is that of O.Max.inv. 356, a first/second-century, bilingual abecedary in which the Greek reader is informed how the Latin letters are to be pronounced. ${ }^{12}$ The Hermeneumata and other surviving compositions (e.g., P.Oxy. LXXXII 5302) indicate a growing focus on speaking rather than on the act of translation, but provide evidence that dual language acquisition was of concern to some communities. Although they represent a later development of the education system, they likely provide an indication of bilingual teaching methods of the Hellenistic era. The dearth of earlier, identifiable school texts likely indicates that a person learned to write their second language in a different setting, such as a different language school or at a later stage of their education (e.g., UPZ I 148). ${ }^{13}$ Despite this lack of primary evidence for interlingual translation of literary texts in the school system, ancient authors did undertake the task of translation, although exactly what this entailed is not easy to determine.

The recognition that elements of translation were included in the education system bolsters the idea that translation was a regular and important task in antiquity.

8 Quintilian, Inst. Or. 1.1.12; Augustine, Conf.1.13-14. By the end of the Republican period the Latin translation of Homer by Livius Andronicus was being used in Latin education (Horace, Ep. 2.1.69-71; cf. Suetonius, Gram. 9). Cf. Cribiore (1996) 9, 148.

9 Cf. Nepos, Gramm. 4.2 = F61 (Teubner).

10 Gayraud (2010) 35-44; Biville (2002) 84-85; Kramer (2001) 30. For a new introduction, translation, and commentary, see Dickey (2012-2015) esp. 1.50-52.

11 Aesop's Fables and Hyginus' Genealogy are also thought to have been used in class settings. Cf. Marrou (1956) 263-64.

12 Cf. P.Ant. I fr. 1; P.Oxy. X 1315. For the appropriation of Latin teaching materials for Greek speakers, see Dickey (2010). For additional evidence of Greek-Latin learning, see the table in Dickey (20122015) 7-10.

13 Cribiore (1996) 30. 
This claim is not surprising, but by framing our discussion of translation in educational terms we see that the foundation for literary translation was laid early in a person's training. Indeed the exposure to Greek authors and literary models is an essential element for the claim by Romans that its literature is a continuation of Greek culture. $^{14}$

\section{Roman and Jewish Translations}

Although a definition of 'translation' can be readily provided by most people, the principles of translation are difficult to articulate and deceptively complex. The process of rendering an element from a source language into a receptor or target language is challenging and there is substantial debate over how these terms should be understood and how this processed should be engaged. ${ }^{15}$ Cultural and temporal distances pose an even greater challenge to scholars of antiquity; we conceptualise and define translation in vastly different ways than the ancients did. In the following sections we will investigate the ways Roman and Jewish authors present their understanding of translation of literary texts. ${ }^{16}$ As representative authors describe specific acts of translation we will notice points of similarities and differences in approaches as well as rationales for engaging in this practice.

\section{Translations by Latin Authors}

The Romans were not the first people in their vicinity to engage with the practice of translation, but were preceded by their Greek neighbours. An early example of this comes from Herodotus, who regularly tells of tales from distant lands, such as those of the Egyptian kings. ${ }^{17}$ For instance, Herodotus recounts the story of an unnamed man who stole from the king in such an ingenious way that king Rhampsinitus offered him his daughter in marriage (Hist. 2.121). Herodotus uses the language of

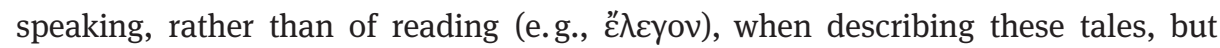
such examples show that foreign stories were beginning to be included within Greek literature and that translation of the tale must have taken place at some level. ${ }^{18}$

14 E.g., Ovid, Amor. 1.15. Cf. Feeney (2016) 4-13.

15 On the difficulties of defining 'translation' and the risks of imposing modern ideas onto ancient authors, see Hermans (2002) 10-23. Indeed, all of the essays in that volume contribute to this discussion.

16 Brock rightly notes that the type of document influences the nature of translation, with legal texts tending to be more 'literal' and literary text translated more 'freely'. Brock (1972) 17.

17 See also the tales of Sesostris (Hist. 2.102-104, 107-10) and Sethon (Hist. 2.141).

18 Cf. Stronk (2011). For some additional references to translation in Greek literature, see Herodotus, Hist. 7.87; Thucydides, Hist. 4.50; Luke 23:38. 
One of the earliest authors to discuss the relationships between different languages, both written and spoken, was Aristotle, who claims in the opening of his Interpretation:

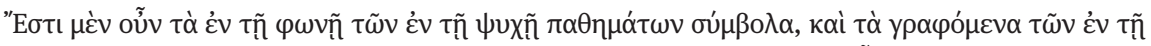

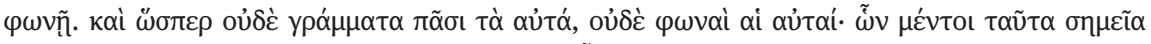

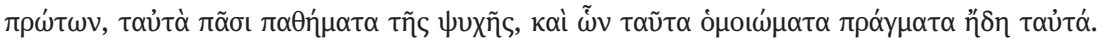

Spoken words are symbols of impressions of the soul; written words are the signs of words spoken. As with writing, so also with speech, it is not the same for all races of people. But the mental impressions themselves, of which these words are primarily signs, are the same for the whole of humanity, as are also the objects of which those impressions are representations or likenesses, images, copies (Int. 1, 16a4-8). ${ }^{19}$

Aristotle recognises the fact that different people groups have different languages and that this dissimilarity is expressed both in word and in script. However, according to Aristotle, the mental impressions of the reality of the world are the same for all people, but are only expressed using conventions that are appropriate to the language of the observer. In this statement, Aristotle asserts that mental impressions and their objects are secure and stable despite the fact that they are viewed by people from different ethnicities and languages. Although not explicit, Aristotle implies that at some level words from differing languages can be equated because they are merely signifiers referring to the same fundamental impression. If one could find the appropriate signifier in the target language, then, according to Aristotle's understanding, one would be able to transfer his or her idea with minimal loss or corruption of meaning because the true nature of the signified is identical in both languages. This statement by Aristotle is brief and, unfortunately for us, Greek authors rarely remarked on the nature of interlingual textual translation, nor was the practice prominent in their literary activity. ${ }^{20}$ As will be discussed further below, this is likely due to the dominant position and high prestige that Greek language and literature held in antiquity. Nevertheless, Roman practice marks an important shift in how translations were viewed and understood in antiquity.

Roman authors were much more interested in literary translation than their Greek neighbours, discussing its nature, purpose, and function for centuries. ${ }^{21}$ In

19 Adapted from Cooke/Tredennick (1938). Cf. Aristotle, Poet. 1457b1-5.

20 Cf. Most (2003) 389. Certain texts (e.g., senatus consulta documents) were translated literally from Latin to Greek, but this direction of translation was not common for literary texts in the Hellenistic and early Roman era. Cf. Brock (1979) 74. Later, Greek translations of Virgil become common, especially as school texts/exercises. E. g., P.Ryl.Gr. 478a-b. The Oxyrhynchus Glossary (P.Oxy. XV $1802+$ LXXI 4812) does show that Eastern languages (i.e., Persian, Babylonian, and Chaldean) were transliterated and glossed for Greek readers. Cf. Schironi (2009). See also the discussion of lexica in Hatzimichali's chapter.

21 For important discussions of the development of Roman translation theory that takes into account the historical situation of the authors, see McElduff (2013); Feeney (2016). 
particular, Roman authors throughout the late Republic and early Principate regularly engaged with Greek literary culture, and as early as the third century BCE we find examples of Homer's works being translated into Latin. ${ }^{22}$ The first individual reported to have attempt this was Livius Andronicus (ca. 284-204 BCE), who in addition to appropriating Greek dramatic works for Latin consumption, rendered Homer's Odyssey into Saturnian verse, complete with latinising names for the divine pantheon. ${ }^{23}$ Livius was not the only person to attempt this feat; Gnaeus Matius and Ninnius Crassus are also said to have translated Homer (Gellius, NA 7.6.5), and Seneca reports that a subsequent translation was attempted by Polybius, a freedman of Emperor Claudius (Polyb. 11.5). ${ }^{24}$

Roman translation methods could be very free..$^{25}$ The difficulty in engaging with two scrolls simultaneously, as well as the practice of working from epitomes or memory, could lead to 'translations' that would hardly be worthy of the term by modern standards. ${ }^{26}$ Such practical issues, however, do not require a free approach to translation. Rather, the author's (and wider culture's) view of the original text and the purpose for engaging in translation are more important factors in this regard. To the Latin translator, the Greek source text was not considered sacrosanct, but could be heavily abridged (e.g., Livius Andronicus) and blended with new material penned by the translator cum author (e. g., Germanicus Caesar's translation of Aratus' Phaenomena). ${ }^{27}$ Such an approach to translation-namely not being too beholden to the original, but trying to improve upon it-is explicitly endorsed by Pliny (Ep. 7.9.4) and Horace (Ars 131-35). These comments support the view that the Roman translators were deeply and unavoidably influenced by their personal, social, and cultural histories, which shaped the way they approached the translator's task. ${ }^{28}$ Not only are

22 Although we will be focusing on literary works, we must also recognise the reality of legal and official translations that were very much part of the wider ancient world (e.g., Rosetta Stone, Augustus' Res Gestae, senatorial decrees, etc.). For a recent discussion of how each language is tailored to their audience, see J. Larson (2011) 50-61.

23 See Courtney (1993) 45-46; Armstrong (2008) 170, 174-75.

24 Not all translations of Homer were thought to be of a good standard and Attius Labeo's 'literal' version of both poems was heavily satirized by Persius (Sat. 1.4-5, 50). Conversely, Baebius Italicus's Ilias Latina recounted the whole of the Iliad in one book and became the standard Latin translation of Homer in the West through the Middle Ages. Cf. Scaffai (1994).

Homer was not the only Greek epic poet translated for Latin readers: P. Terentius Varro Atacinus (b. 82 BCE) made a translation of Apollonius' Argonautica (Quintilian, Inst. Or. 10.87). Cf. Courtney (1993) 238-43. Cf. Terence, Eun. 7-8.

25 There is much literature on the definitions of 'free' and 'literal' with regard to translation. In this chapter, I am not using them technically, but to approximate the relative relation between source and rendered texts. For a more thorough discussion and problematisation of this concept, see Barr (1979); Davila (2005).

26 Cf. Cicero, Att. 2.6.1; Pliny, Ep. 3.15.17; 7.9.1-16.

27 Gellius (NA 1.3.11-12) speaks of Cicero omitting and condensing sections of Theophrastus' On Friendship in his 'translation'.

28 See the foundational discussion of Siméoni (1998) esp. 32. 
translators constructs of their society, they are at the same time constructors of the inherited wisdom of future translators; they are both shaped by and are shapers of tradition. The translators in their work are constrained (to some extent) by the expectations of their readers. At the same time they seek to adjust their received expectations so as to promote and achieve their own personal goals. As a result, the act of translating literature in the Roman world is highly complex and the translator must navigate multi-currented waters if he or she is to succeed in his or her endeavours.

Translation can also be seen as a tool of the conquerors and of the powerful. Rome, in their subjugation of Greece, not only took their freedom and wealth, but also repurposed their literature to tell a new, Roman story. Romans were aware of the cultural superiority of the Greeks and many of the authors of surviving Lain texts express a deep dissatisfaction at this imbalance and a desire for Latin language and literature to be elevated so as to (at the minimum) become a peer to Greek. ${ }^{29}$ This understanding is well expressed by Crassus in Cicero, De or. 1.155:

\footnotetext{
Postea mihi placuit, eoque sum usus adulescens, ut summorum oratorum Graecas orationes explicarem, quibus lectis hoc adsequebar, ut, cum ea, quae legeram Graece, Latine redderem, non solum optimis verbis uterer et tamen usitatis, sed etiam exprimerem quaedam verba imitando, quae nova nostris essent, dum modo essent idonea.

Afterwards I resolved-and this practice I followed when somewhat older-to translate Greek speeches of the most eminent orators. The result of reading these was that, in rendering into Latin what I had read in Greek, I not only found myself using the best words (and yet familiar ones), but also coining by analogy certain words such as would be new to our people, provided that they were appropriate (trans. Sutton and Rackham).
}

Translation for Crassus, in addition to developing his oratorical skills, also becomes a civic duty to one's nation, a way to benefit the Roman people. ${ }^{30}$ Similarly, Cicero's critique of his countrymen who prefer Greek literature over Latin also addressed the necessity of translation for the development of Latin literary culture (Opt. gen. 18). More importantly, these translations will wrest control from Greek authors and place it firmly in the hands of Rome, eliminating the dependence on Greek libraries and authors (Cicero, Tusc. 2.5-6) and establishing a new benchmark for Latin reading (Opt. gen. 23). This requires that the translator add his own voice to the newlyformed work and does not translate the text overly literally; 'for it is easy to translate (interpretari) thoughts, that I could do if I did not wish to be myself' (Cicero, Leg. 2.17). ${ }^{31}$ Fidelity to the text, therefore, does not become the primary purpose of

29 Cf. Cicero, Tusc. 1.3-6; Acad. 1.4-5, 10; Leg. 1.5-6.

30 McElduff (2013) 10. Cf. Cicero, Fin. 1.4-6, 10; Acad. 1.5. For a detailed discussion of Cicero's practice of introducing Latin glosses to Greek philosophical terms (e.g., globus for $\sigma \varphi \alpha \tilde{p} \alpha$ ), see Sedley (2012) $189-92$.

31 At times, Cicero claims to make literal translations (e.g., Tusc. 3.37; Div. 1.61, 'I have reproduced Plato's very words [verba ipsa]'.), although his closeness to the original text is questionable (cf. 
Latin translation as it would render the translator mute and so perpetuate the voice of the Greek original..$^{32}$ Rather, translation among Latin authors becomes a method of control and rebranding, allowing the original to say only what they wished it to say (e.g., Cicero, Off. 1.6). Indeed, to be too faithful to the text would undermine the intention of translation, namely to imbue previous Greek thought with Roman ideals and to provide a new voice for the Roman populous. ${ }^{33}$

This move away from the strict translation of the original towards a creative repurposing is highlighted by the attribution of a new authorial name to the work. These Latin translations are not to be done anonymously, as many translation works were in antiquity. Rather, they signify their compositional stamp by actively claiming the 'new' work as their own. Furthermore, reattribution is found in a range of literary genres (e.g., epic, tragedy, comedy, philosophical texts, etc.), which helps distinguish this practice from the rote translations of legal and other documentary texts. ${ }^{34}$ Accordingly, Latin translation becomes another form of conquest, whereby formerly Greek accomplishments are co-opted and become part of Latin literary culture. ${ }^{35}$

One important consideration for these discussions by Latin authors is the assumption on their behalf that the readers of Latin translations would have access to the original, source-language text. As members of the Roman educated elite would likely have also read the original text, the translator was not compelled to replicate the original, nor was that his primary purpose for engaging in translation ac-

Fin. 3.15). For Cicero's famous comparison between word for word translations and those engaged by orators, see Opt. gen. 14; Jerome, Ep. 57.5.

32 On the other hand, it does appear that Cicero thought that some instances of translation required greater fidelity to the original (e.g., Fin. 1.7), but here in the tradition of Ennius and Afranius it still allowed for variation. Cicero's close adherence to a source text is found most prominently in the surviving fragments of his translation of Plato's Timaeus, but, as far as we are aware, Cicero still felt free to add glosses and to omit parts of the text (e.g., the entire conversation preceding Timaeus' speech and Timaeus' opening prayer). For a full list of Cicero's translations from Plato, see Powell (1995) $279-80$.

However, note the claim by Terence (Ad.7-11) that he included a passage of Diphilus' comedy, Comrades in Death, that was omitted by Plautus and that he translated it 'word for word' (verbum de verbo). Unfortunately, as the Greek play is lost, we have no way of determining the veracity of Terence's claim. Cf. Dares of Phrygia, De excidio Troiae historia 5-10

33 Not all translations do this. Cicero laments that poor translations, made from inferior Greek texts, give Latin philosophical writings a bad name (Fin. 1.8; cf. Fam. 15.19.2).

34 E.g., Attius Labeo (Courtney [1993] 350); Plautus, Bacchides; Cicero, Off. 1.6. For a named Latin translation of Aesop's Fables (by Quintus Ennius) complete with additional Latin moralisation, see Gellius, NA 2.29.20.

35 One potential counter example to this would be the need by Greek authors to use Latin sources for their composition. One instance of this would be Plutarch's use of Livy in Marc. 11.4; 24.4; 30.4; Thanks to Elizabeth Corsar for raising this point. For a foundational discussion of the use of Latin in the Greek East, see Rochette (1997). 
tivities. ${ }^{36}$ Rather, the translator would be judged by his ability to make creative use of his model and through this adaptation his own originality and skill would be expressed. ${ }^{37}$ This textual duality and synoptic reading practice fundamentally changes a perceived rationale for engaging in translation, namely, to make the source text available to a readership to which it was previously excluded. ${ }^{38}$

One final point is needed to be highlighted prior to turning our attention to Jewish authors, namely that all of the above mentioned author are elite members of Roman society. Although this is not surprising, given the way that literature is written and preserved from antiquity, we need to be aware that social issues are likely also at play. Cicero's (and other's) comparison between orators and 'interpreters' (interpres) embed class distinctions (e.g., Opt. gen. 14; Leg. 1.14.9; Rhet. Her. 2.16.11) and reinforce, not a particular type of translation practice, but the hierarchy of who is worthy to bring Greek literary works into the Latin fold. ${ }^{39}$ Such a perspective has at its heart the struggle for power and control, not only within Latin culture, but also how Latin literary culture engages with its Greek conquests.

This brief discussion of Roman translation practice and debates provides an important counterpoint to how Jewish authors, who are political and cultural minorities, understand and describe their act(s) of translation.

\section{Jewish Authors and Translation}

Jewish scholars were active translators throughout the Hellenistic and Early Roman eras. ${ }^{40}$ Although a lot of translated works, such as the Septuagint and Sirach, are thought to be translated in Egypt, ${ }^{41}$ there is evidence that translation into Greek

36 So Marrou (1956) 255.

37 E.g., Cicero, Acad. 1.8. Cf. Bassnett (2014) 55.

38 For examples of comparison of Greek and Latin texts, see Gellius, NA 2.23; 13.31 .17 (cf. Cicero, Nat. d. 2.91); 17.10 (comparing Pindar, Pyth. 1.21-26 and Virgil, Aen. 3.570 - 577).

39 McElduff (2009). Copeland rightly highlights that this distinction also encodes an expectation of one's level of education and thus disciplinary boundaries (e.g., Cicero, De or. 1.187). Cf. Copeland (1991) $16-30$.

40 For the different translations of the LXX over this time period, see Fernández Marcos (2000) 109-87. For later Jewish translation endeavours, see de Lange (2015).

Jews were not the only people group to translate texts into Greek in the Hellenistic Era. For example, we have evidence that the Demotic Manual of law was translated into Greek (cf. P.Oxy. XLVI 3285) as well as the Oracle of the Potter (P.Oxy. XXII 2332). Similarly, select pieces of Egyptian literature have also been rendered into Greek. The Dream of Nectanebo and the Tale of Tefnut both are thought to be translated works, and the Coptic version of Tale of Tefnut and the Demotic version of the Dream of Nectanebo survive. Story of Sesonchis might also be considered a translated work. Fraser (1972), 1.676; Cf. West (1969); Rutherford (2016) esp. 5-16.

41 E.g., Sirach, Praef. 27; Letter of Aristeas, passim. Cf. Joosten (2012) 185-239. On translations of legal texts, including the Septuagint and the Demotic Case-Book, see Mélèze-Modrzejewski (1995) $1-19$. 
also occurred in the heart of Judaea. ${ }^{42}$ For example, the colophon to Greek Esther states that it was 'translated by Lysimachus son of Ptolemy, a member of the Jerusa-

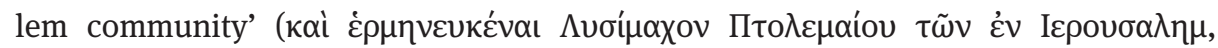
10:3 1, F11). Although this declaration of Jerusalem translation is distinctive, this act of translation is not unique as recent studies have found that the linguistic situation in Roman Judaea was diverse and more complex than previously acknowledged. ${ }^{43}$

Translating literary works from Hebrew or Aramaic into Greek, some Jewish translators explicitly acknowledged the challenges of translation and the inability of the target language to capture the nuance and force of the source language. ${ }^{44}$ For instance, the translator of Sirach, in the preface to his grandfather's work (Praef. 15-26), declares that his work, as well as those that have gone before, are

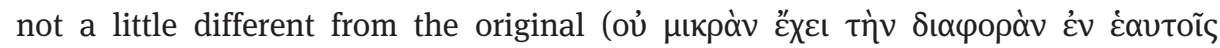
$\lambda \varepsilon y o ́ \mu \varepsilon v \alpha$, Praef. 26). ${ }^{45}$ In this case the author was not lamenting the inability of the target language to capture the meaning of the source language. Rather, the apology is that by adhering closely to the structure and meaning of the Hebrew the force and impact of the original is lost in Greek: 'For those things originally in Hebrew do

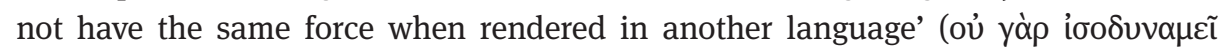

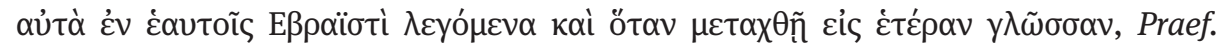
$20-21){ }^{46}$

Of primary importance for this paper is the Letter of Aristeas and its literary depiction of the translation of the Septuagint. ${ }^{47}$ It is rare for a work from antiquity to have translation as a major theme, which had led Aristeas to be the focus of a number of scholarly studies. ${ }^{48}$ Set in the Alexandrian royal courts, the opening and clos-

42 Recently, Aitken has provided a detailed study of Jewish and Egyptian documentary translation techniques, highlighting similarities between surviving Demotic documents and the Septuagint. See Aitken (2016). For a nuanced consideration of the LXX in light of Greek inscriptions in Egypt, see Aitken (2014).

43 E. g., the Greek scroll of the Minor Prophets at Nahal Hever (8HevXIIgr) and the Greek fragments found at Qumran: 4Q119; 4Q120; 4Q121; 4Q122; 7Q1; 7Q2. Cf. Hengel (1974). This is most recently argued by Wise (2015).

44 Such a literary apology is rarely a concern for Latin literary translations. So Fewster (2002) 232; Rajak (2009) 136. However, cf. Gellius, NA 17.20.8.

45 Ziegler (2016).

46 Cf. Iamblichus, Myst. 7.5; Seneca, Polyb. 11.5; Gellius, NA 11.16. Cf. Aitken (2011). For the view that the apology is for the poor quality of the writing, as opposed to deviation from the Hebrew, see Wright (2003) 11-20.

47 Shutt's translation of Aristeas 9-10 implies that other texts, in addition to the Jewish Scriptures,

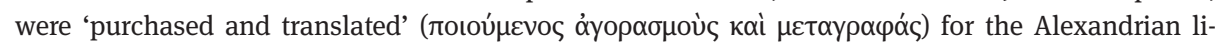
brary. Although this translation is possible, it is better rendered 'purchased and transcribed' as $\$ 11$

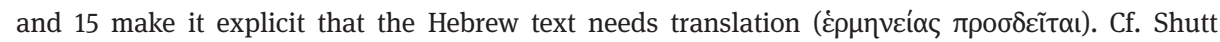
(1985) 12.

48 Honigman (2003); Niehoff (2011) 19-37; Matusova (2015); Wright (2015). For the edition used, see Pelletier (1962) $100-240$. 
ing of Aristeas tells the story of the 'translation' of the Hebrew Scriptures into Greek $(\S \S 9-11,301-321)$ and recalls all of the pomp and ceremony surrounding this process. The text is written to Philocrates (§1) from the perspective of Aristeas, a Greek administrator reported to be involved in the events. Both characters are Greek in ethnicity and so provide an 'outsider's' perspective to the events. The text, however, is Jewish in origin, written by an unknown author likely in the second century BCE. ${ }^{49}$ The proposed narrative rationale in Aristeas is that Philocrates has a deep love of

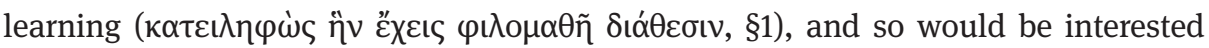
in Aristeas' experiences and this Jewish text. ${ }^{50}$

In light of the work's literary setting in Alexandria, there has been a move recently to read Aristeas as part of Alexandrian literary culture and to compare the contents of the text to then contemporary Greek methods of textual scholarship. ${ }^{51}$ One of the first indications of this perspective is the use of specific scholarly vocabulary in $\S \S 30-32$ :

Toṽ vó

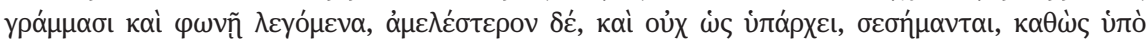

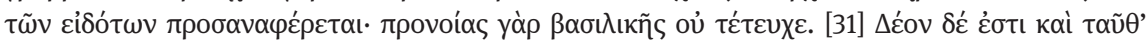

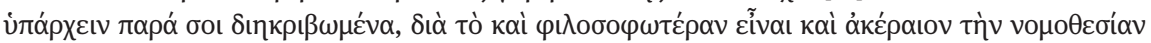

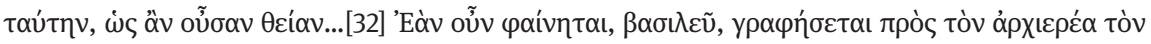

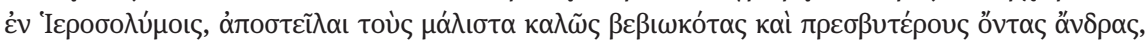

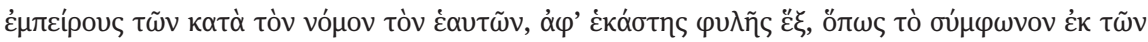

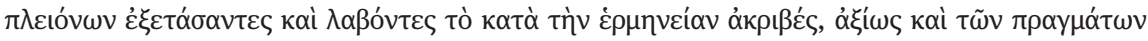

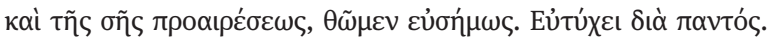

The books of the law of the Jews (with some few others) are absent from the library. They are written in the Hebrew characters and language and have been carelessly transcribed and not as they should be, according to the reports of experts, for they have never received royal patronage. These [books] should also be for you in an amended form since this legislation is both most philosophical and pure, inasmuch as it is divine... If it pleases you, $\mathrm{O}$ king, a letter shall be written to the High Priest in Jerusalem, to send men who have lived noble lives and are mature, skilled in their law, six from each tribe, so that after the examination of the text and the agreement of the majority, and receiving an accurate interpretation/translation we may place it conspicuously [in the library], worthy of the deed and your purpose.

In this passage Aristeas emphasises the need for well maintained and curated texts that come from an accurate source text. Ancient scholars were aware that not all texts were equal in quality and that the best texts were regularly held in the originating city's archive/library. ${ }^{52}$ In this case, the focus on Jerusalem aligns well with the

49 Wright (2015) 21-30.

50 The reader is also thought to share Philocrates' love of learning $(\S \S 7,171,300)$ and interest in the Jewish people, religious topics, as well as the ultimate importance of piety $(\S \S 2,5)$.

51 So Honigman (2003); Niehoff (2011) 19-37; Matusova (2015).

52 E. g., the texts of Sophocles, Euripides, and Aeschylus held at Athens. Cf. Galen, Commentary on the Epidemics of Hippocrates 2.4, Kühn (1821-1833) 17.1.607-608; Gellius, NA 1.7.1. For a discussion of the importance of the author's personal copy, see Gellius, NA 1.21.2. 
scholarly practice at Alexandria to secure the best text editions for study. The previ-

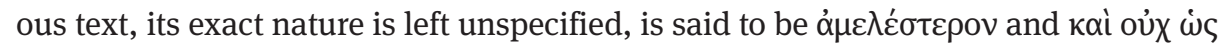

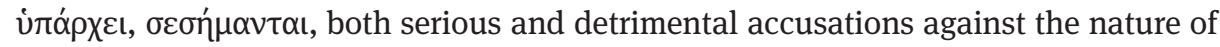
the current text.

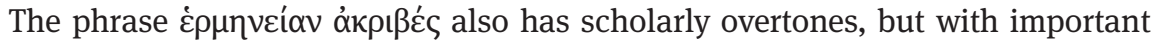
ambiguity as it expresses exactness, either to ‘(scholarly) interpretation' or to ‘translation'. ${ }^{53}$ The recurring use of the term $\dot{\varepsilon} \rho \mu \eta v \varepsilon i ́ \alpha$ in Aristeas $(\S \S 3,11,32,120,301,308)$ is one of the distinguishing features of this narrative as the author describes the work of the Jewish translators using this term and not the more explicit $\mu \varepsilon \theta \varepsilon \rho \mu \eta v \varepsilon u ́ \omega$, 'to translate'. The term $\mu \varepsilon \theta \varepsilon \rho \mu \eta v \varepsilon v ́ \omega$ is used in $\S 38$, but it is in the letter from the king ( $\S 35-40)$ and so does not represent the viewpoint of Aristeas or the Jewish scholars within the text. A similar ambiguity is found in the use of $\mu \varepsilon \tau \alpha y \rho \alpha y$ ', 'transcription' $(\S \S 9,10,15,45,46,307)$, which could also imply translation, but does not have sufficient clarity within the narrative. ${ }^{54}$

In the final section of Aristeas (\$§301-307) we return to the theme of translation and in $\$ 302$ the author provides a description of the process undertaken by the Jerusalem scholars: 'and they accomplished it, making each detail agree by comparison

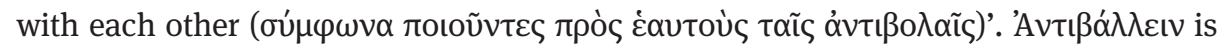
a technical term for the collation of manuscripts and is coherent with the expressed desire to have an accurate text earlier in the narrative. This is followed by the reading

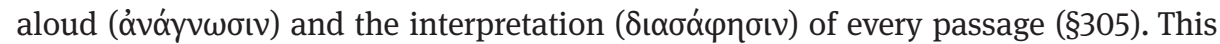
process is parallel to that described by Dionysius Thrax (Gram. 1.1.5), who argued that

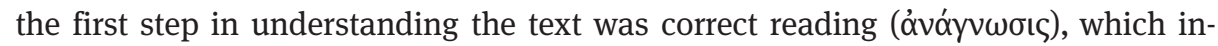
cludes expression, intonation, and divisions, and was to be followed by the interpre-

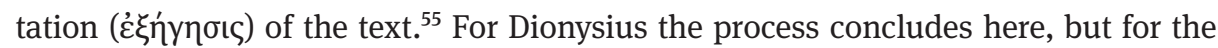
Jewish authors in Aristeas an additional step is required, namely, rendering the nowunderstood text into a new target language. Matusova argues that applying Greek grammatical theory to the translation of a work is an 'unprecedented adaptation' and has strong implications for ancient translation theory. ${ }^{56}$ This is a bold claim, but not completely unwarranted, as the most striking feature of Aristeas is that the author does not describe the scholarly activity through translation language, but with editing vocabulary. The author of Aristeas could have used such terms when discussing the creation of the Greek version, but instead he employed alterative language which has strong resonances with Alexandrian scholarship in general and Aristarchus in particular. ${ }^{57}$

53 Zuntz (1959) 121-22.

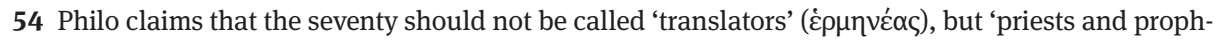

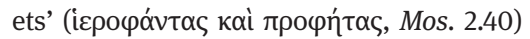

55 van der Kooij (1998) 222.

56 Matusova (2015) 84. See most recently, Matusova (2018).

57 Montanari (2015) esp. 1.86-89; Wright (2008). 
What is important to recall here is that the account in Aristeas is not to be taken as a straight, unadulterated description of events that actually happened, especially in light of the strong difference between the LXX and the Aristeas narrative. ${ }^{58}$ This is not to say that the narrative is devoid of historical facts, or that it could not be used for historical reconstruction, but that the text is inherently ideological and that the author had a specific communication goal in mind. ${ }^{59}$ The discussion of the "translation' in terms of text-editing vocabulary is a strategic move on behalf of the author, one that employs current ideas and methodology and transfers them back to the time of Ptolemy II. ${ }^{60}$ The publication of Aristarchus' edition of Homer around the time of Aristeas' composition represents the pinnacle of Alexandrian text criticism and set the standard for future editions of texts. It is questionable whether or not the original translators employed grammatical methodologies; however, it is apparently important to the author of Aristeas that the Jewish translators appeared to have done so. The use of Greek scholarly vocabulary, therefore, frames the discussion and depiction of Greek Scripture and is employed by the author to show that the translators adhered to the best of Greek scholarly practice. Moreover, this practice was almost exclusively used for literary works, and so in making this parallel the author imputes a literary quality to the work. ${ }^{61}$

One of the more obvious suggestions for the adoption of this presentation was the desire to present the Jewish scholars, especially those outside of Alexandria, as knowing and using advanced reading techniques. In the contest of cultures the author of Aristeas is making a statement regarding the Jewish people and their level of literary sophistication; the seventy-two Jewish scholars from Jerusalem are not under-equipped for the task, nor is their city a backwater metropolis lacking proper education. ${ }^{62}$ A major theme of Aristeas is the fact that the Hebrew text and its translators come from Jerusalem; ${ }^{63}$ these translators are fully conversant with the current trends of scholarship and are able to excel in such tasks. Indeed, the fact that these scholars are named (\$\$47-51; cf. Josephus, Ant. 12.57), a practice

58 Cf. Wright (2006) esp. 59-61.

59 For a less complementary position, see Zuntz (1959) 123, who states, 'He who strives to elicit historical facts from this narrative is building on foundations very much less solid than sand'. Cf. Janowitz (1991).

60 Contra Zuntz (1959) 122, who writes 'however abstruse it may seem that he should have chosen to represent the translators' task as a work of critical scholarship'.

61 In addition, Ps.-Aristeas presents the original Hebrew text as a philosophical work and not only a legal text (\$31) and the translation being undertaken by Jewish philosophers and not scribes/interpreters (\$235).

62 On the parallel between the 72 Jewish translators and the 72 editors of Homer commissioned by Pisistratus, see Matusova (2015) 54-61.

63 Although unstated, the need to import translators and the high praise given to them implies a deep inadequacy of the Jews currently living in Alexandria and in Egypt more broadly. This motif is in tension with the claims by a number of scholars that the historical translators of the LXX hailed from Alexandria. E. g., Swete (2000) 20 -21; Dines (2004) 33; Honigman (2003) 97. 
that is notably absent in other surviving Jewish-Greek translations (including the Septuagint), suggests that the author of Aristeas was attempting to raise the literary profile of the Greek text, thus implying literary aspirations. Although this is certainly what the text presents, it is not the full explanation of the author's motivations.

The author of Aristeas also makes declarations regarding the nature of texts, namely that the earlier edition(s) was flawed and that the new text from Jerusalem is superior, both surpassing and replacing previous versions held at Alexandria. It is this authorised text that forms the basis of the translation and which lends its authority to the new version. The use of grammatical language might also suggest that, in the mind of the author of Aristeas and/or his contemporaries, the founding of the Greek version of Scripture was of the same magnitude as the establishment of Homer's text. ${ }^{64}$ As Aristarchus' texts was thought to be the pinnacle of editorial achievement, ${ }^{65}$ so too the author of Aristeas presents the LXX as perfectly accurate ( $\pi \tilde{\alpha} v$

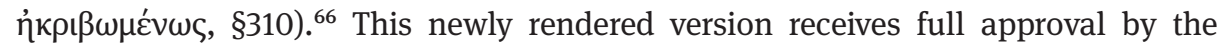

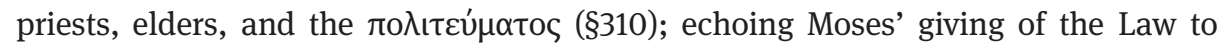
the people at Sinai. ${ }^{67}$ More importantly for our discussion is the claim that the Greek translation perfectly represents the original Hebrew. This fits with the larger prohibition expressed in $\$ \S 310-11$ that no further revision should be undertaken to the text. Such prohibitions against modifications are part of the process of text establishment and have strong parallels to the revealing of the Law at Sinai. ${ }^{68}$ This understanding also works with the larger narrative construct and the establishment of an official version of the text in the royal library. ${ }^{69}$

64 Honigman (2003) 120; Honigman (2007) 128. This perspective is critiqued by Matusova (2015) 79-82, who highlights the differences between Homer and LXX regarding style (poetry/prose), quality (good/poor), and prestige (high/low). Although Matusova is correct in her assessment, I think she downplays the perspective of the Jewish scholars and their view of Scripture as a possible parallel to the importance of Homer's works for Greeks.

65 Pfeiffer (1968) $210-33$.

66 Similarly, Philo (Mos. 2.40) also highlights this perfection through the translators communing with the spirit of Moses and guided by a divine hand. Cf. Kamesar (2009) 66-72.

67 Wright (2015) 443-44.

68 Orlinsky (1975); cf. Brock (1992). Philo, Mos. 2.25-44 highlights the divine character of the LXX and the inspired nature of the translators (esp. 2.37).

69 As an aside, consideration should be given to Rewritten Scripture as a potential translation of the biblical text (e.g., Jubilees, Josephus' Antiquities, Ps.-Philo's LAB; Genesis Apocryphon [1Q20], 11QTemple Scroll [11Q19], and 4QReworked Pentateuch [4Q158]). Rewritten Scripture is not often categorised in this way, but it might be profitable to think about it in terms of intralingual translation. This differs from the examples of interlingual translation above, but one could argue that educated Jewish authors, in some cases, were a part of both Hebrew and Greek literary cultures and so the 'translation' from Greek to Greek would differ little from Hebrew to Greek translations in terms of accessibility. More importantly for our discussion, this type of literary practice parallels Greek to Latin conversion, as that too could be considered a form of intralingual translation, since Latin authors were as much part of Greek literary culture as they were of Latin culture. Additionally, as mentioned above, there were attempts by Latin authors to rewrite Livius' translation of Homer, an activity that 


\section{Similarities and Differences between Roman and Jewish Translations}

We now turn our attention to contrasting the approaches of Roman and Jewish authors based on the above discussion. The first and most obvious similarity in our study is that both groups depicted themselves, and not others, as engaging in acts of literary translation. This is not to say that Jewish and Roman authors would not have recognised the activities of other groups, but that both are focused primarily on their own actions.

Second, the language that both Roman and Jewish authors translated to and from was Greek. Although this might appear obvious, both Jewish and Roman authors had other linguistic options. For example, Jewish authors in Egypt could have translated their texts into Demotic, but, as far as we know, this was not the case. ${ }^{70}$ Similarly, Latin was an increasingly prevalent option, but this choice was almost universally declined. The selection of which texts to translate and the direction of translation (i.e., to or from Greek), however, is an important and fundamental difference. Latin authors, it appears, were not interested in translating their texts into Greek or making their texts readily available to other cultures in native languages. ${ }^{71}$ Instead, all of the reported translations from the Republic and Early Empire are intended to make texts from other languages known to Latin readers, bring the literary wealth of other cultures under Latin influence through 'translation' ${ }^{72}$

In contrast, Jewish (and other minority cultures) translators selected their own texts for translation into the then dominant language. As a result, in addition to the common choice of translating literary (i.e., non-technical) texts, something that was not a given in antiquity ${ }^{73}$ we witness a clear flow of translation activities, from those with little influence or standing towards the dominant cultural and polit-

parallels the Jewish practice of reworking translations for a new audience/purpose (e.g., Ezekiel Tragicus, Philo Epicus, Theodectus in Aristeas 316). Thanks to James Aitken for helping develop this idea. For recent discussion of the nature of Rewritten Scripture, see Bernstein (2005); Brooke (2010); Machiela (2010); Zahn (2012). For later changes to Livius work and the re-writing of it in hexameter, see Courtney (1993) 45-46.

70 Other linguistic choices were made by Jewish authors in different geographic situations. For example, the translations of the Hebrew Scriptures into Aramaic (i.e., the targumim) did not take place in Egypt, but in Judaea and further east (esp. Babylon).

71 Nevertheless, in late antiquity, there were a number of Greek translations of Virgil. Cf. P.Gongr. XV 3; P.Oxy. L 3553; P.Vindob.inv. L 24; L 62. A similar direction of translation is found in Syriac, in which few Syriac texts were translated into Greek, but many from Greek into Syriac. Cf. Brock (1977).

72 This is not to claim that Greek was not considered a prestige language in Rome or among the Roman literary elite; there was a complex relationship between the two languages. The Latin authors above recognise the importance of Greek, but concurrently desire to undermine it through the advancement of Latin language and literature. For the discussion of prestige with regard to language, see Hudson (1980) 32-34; Dixon (1997) 9-10. On Graeco-Egyptian translations, in both directions, and the relationship between Greek and Demotic, see Rutherford (2016).

73 On this important point, see Feeney (2016) 152-78. 
ical power. ${ }^{74}$ The directionality and selection of target language is a major difference and one that is highlighted especially by Latin authors, many of whom argue explicitly that translating Greek works into Latin not only provides a benefit to Latin readers, but also enriches the Latin language; an action that profits the entire nation. This explicit motivation is not highlighted in some depictions of Jewish translations, ${ }^{75}$ but is expressed throughout Aristeas, which shows awareness by the author that this was an important consideration for cultural acquisition. ${ }^{76}$ As a result, the translation of Jewish Scripture into Greek is presented as a cultural achievement, one that would benefit both Jews and Greeks alike.

This difference in target language further emphasises the different relationships that each group has with Greek culture and their position with regard to cultural power. ${ }^{77}$ Although both Roman and Jewish authors recognise the importance, even perhaps superiority, of Greek culture, they take different approaches to translation based on their perceived relationship with it and the relative status of each language within their respective communities. For the Roman authors, Greek culture might be superior, but they are the dominant political power. Translation for Latin authors is a continuation of this conquest, expressing a desire for dominance. Jewish authors, on the other hand, are politically dominated, both in Egypt and in Judaea, and some scholars have interpreted the translation of Jewish Scriptures into Greek as a means of cultural survival. ${ }^{78}$ For Jewish authors, the approach to Greek texts taken by the Romans was untenable; they could not exert power in such an overt manner. Jewish authors did engage in cultural negotiation and comparison, but more often it was achieved through the construction of alternative narratives, rather than discussions and depictions of translation. ${ }^{79}$

74 A similar practice is seen in the translation of Demotic texts into Greek. Quack (2005) 172.

75 E.g., Philo, Mos. 2.40; Josephus, Ant. 12.101-109.

76 As Greek was the language of many Diaspora Jews, it is possible that the translation of Jewish texts into Greek allowed their community to have a richer vocabulary. More importantly, Greek was recognised as an important language in Egypt with high prestige, as is indicated by the number of Jewish and Egyptian authors writing in Greek (E.g., Manetho, Aristobulus, Philo, etc.).

77 Cf. De Crom (2011) 77-87.

78 E.g., Rajak (2009). For a recent study that argues that the author of Aristeas is concerned with ethnic identity, see Moore (2015) 205-54.

79 Many Jewish texts written in Greek make specific claims about Jewish cultural superiority and how Egyptian and Greek cultures are actually derivative of it (E.g., Philo, Leg. 1.108; Her. 214; Spec. 4.61; Prob. 57; Mos. 2.12, 18-20; Artapanus, F1.1; F2.3; F3.4; Ps.-Orpheus vv. 27-28, recensions B and D; Aristobulus F3.1; F4.4; Eupolemus F1). These claims did not go without response, at least by Egyptian writers. For example, Manetho provides an alternative narrative for this debate from an Egyptian perspective, denigrating Jewish history in an attempt to undermine Jewish claims and bolster their perceived cultural authority. Specifically, Manetho (as reported by Josephus), claims that Moses (F3.37//CA 1.279) and the Jews (F3.20//CA 1.229, 233) were lepers, and that Moses was an Egyptian (F3.3//CA 1.250), who opposed Egyptian cults (F3.4, 12//CA 1.239, 244, 249), and fled to Ethiopia (F3.7-10//CA 1.246-47). For the connections between Artapanus and Manetho, see Freudenthal (1875) 161-62; Fraser (1972) 1.705-706; Barclay (1996), 129-30. 
Another important difference is the determination of which texts were worthy of translation. The texts translated by Latin authors were all of high cultural value and primarily Greek in origin. The notable exception was when, in 146 BCE, the Roman Senate commissioned a Latin translation of Carthaginian Mago's On Farming despite the fact that, as Pliny notes, Cato the Elder's On Farming was already published (cf. Pliny, Nat. 18.22-23). ${ }^{80}$ This was a very large undertaking due to the size of the work (twenty-eight volumes) and so must have been deemed important for the Roman people. ${ }^{81}$ This was a rare instance of official recognition given to a foreign, nonGreek work especially as the rest of the Carthaginian libraries were not thought to be worth keeping and so given to the Numidian kings (regulis Africae). ${ }^{82}$ Moreover, this task was given to a group of translators (Nat. 18.23), a practice markedly different from the individual efforts by Latin authors discussed above.

This picture of state-funded scholarship parallels the depiction of the translation of Jewish Scriptures in Aristeas. In both cases the foreign text, which is taken from the respective capital cities, is presented as being valuable to the dominant nation and so is worthy of consideration. ${ }^{83}$ The perceived significance of the text results in state-funded patronage, which includes the establishment of a team of translators (with a clear leader) and the preservation of the translated text in official archives. ${ }^{84}$

In light of such claims of cultural heritage, the use of Greek language for translations may not solely or necessarily be a capitulation to dominance, but may also be a practical necessity. Scholars debate the levels of Hebrew and Aramaic that survived in both Alexandria and the Egyptian chora. The translator of Sirach implies in his prologue that one of the reasons that he translated the Hebrew work was because he desired that the wisdom of his grandfather be available to those living abroad in

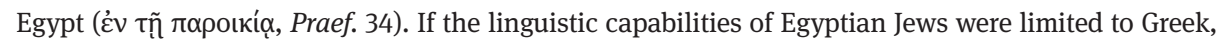
then the translation of Jewish Scriptures into Greek could also embody a practical consideration. Cf. Tcherikover/Fuks (1957) 30 -32. On the bilingual situation of Egypt, see Rochette (1996); Papaconstantinou (2010).

80 See also the commission of Pompeius Lenaeus by Pompey to translate the Greek medical treatises captured from Mithridates' library (Pliny, Nat. 25.5-7).

81 It was used by a number of later authors. E. g., Varro, Rust. 1.1.10; Columella, Rust. 1.1.13.

82 The only other known example of a Latin translation of a Punic text comes from Sallust, who had the geographic work of Hiempsal translated so he could use it as a source for his history (Bell. Jug. 17.7).

83 So Zuntz (1959) 120; cf. Aristeas 175-79.

84 Although D. Julius Silanus is said to be superior for this task, Pliny suggests that the translation process was undertaken by a number of individuals (Nat. 18.23). On the high priest, see Diodorus Siculus, Bibl. 40.3.6. The vital difference between the two narratives is that we have strong evidence in support of the historicity of Mago's translation, whereas, the historical veracity of Aristeas' narrative is suspect. One possible rationale for these parallels is that the author of Aristeas knew of the Mago incident and adapted it. The similarities in the date of the sacking of Carthage and the composition of Aristeas make this possible. A more likely explanation, however, is that the processes of statefunded scholarship were well known and that its schema was adapted by the author of Aristeas.

Another example of royal patronage for translation is found in the preface to Dictys Cretensis' Journal of the Trojan War, a second century CE work that recounts how the Phoenician text was discovered during the reign of Nero and that Nero, recognising the script, called for it to be translated 
Another important difference between Roman and Jewish depictions of literary translation was the perceived importance of the original text and its accuracy. Among Latin authors there was essentially no discussion as to the quality of the texts that they were translating from Greek. This silence likely does not stem from ignorance or ambivalence to this topic, but that it (presumably) was not required since the Latin readers would have had access to a version of the original and that the translation differed (sometimes dramatically) from the original that textual accuracy was not an issue. In contrast, the author of Aristeas was very explicit regarding the importance of textual accuracy and that this was a needed step prior to translation. ${ }^{85}$ This is expressed most prominently through the strong use of scholarly language throughout the text.

Related to the idea of textual accuracy is the rendering of the text into the target language. The 'free' rendering embraced by Latin writers stands in sharp contrast to the depiction of close translations of Jewish authors. ${ }^{86}$ In connection with our discussion of education practices, Pietersma has suggested that the Hebraic nature of the Greek is a result of its origins in the classroom. ${ }^{87}$ In his perspective, the 'interlinear' pairing of the Greek with the Hebrew created a 'crib' to understand the original. This certainly could be the case and Pietersma's parallel with Homer is interesting. He is no doubt correct that 'translations' of Homer were part of the standard classroom practice (see above). What does not necessarily follow from Pietersma's Homeric analogy is the rigid adherence to the source. Homeric exercises could result in close paraphrases, but also in paraphrases and rhetorical retellings that strayed sub-

into Greek and placed in the library. This work was later translated into Latin by a certain Septimius, as is indicated by the opening letter. For a recent discussion of this text, see ní Mheallaigh (2008) 406-14. Thanks to Matthew Nicholls for bringing this text to my attention. For further discussion of this schema, see Adams (2018).

85 The translator of Sirach did not mention this issue; however, as the grandson of the author, it may be widely thought that he had access to the/an original copy. A similar perspective could be held for the translation of Esther in Jerusalem.

86 The literalness that the Septuagint translators adopted, both in reality and in literary depictionsto the point of occasional incomprehensibility of the Greek-reflects the original document and the function of the translated work, both of which are influenced by traditional translation practices. Although some have claimed that it is the sacred nature of the original that inspired such close linguistic alignment, this need not be the case. The translation style adopted by the translator of Sirach, as mentioned in his preface (Praef. 24-25), is similar to that of the Septuagint. It is possible that the translator was not aware that he could translate in a different way (So Wright [2003] 20); however, it is equally possible that he adopted this approach because of his respect for his grandfather's text and the growing tradition of translating works (scripture and scripture-like included) in such manner (cf. Aitken [2016]). That the methodology applied in the creation of the LXX became influential in later translations is clear, but more work is needed to determine its exact influence.

87 Pietersma (2002) esp. 347-49. 
stantially from the original. ${ }^{88}$ Of greater importance for this study is the idea that the author of Aristeas describes the translation, not only in grammatical ideals, but also in terms of fidelity. ${ }^{89}$ In doing so, the author presents the Septuagint in terms that educated readers would understand and approve, but also in a way that differs from Roman discussions.

The religious nature of the text and its veneration by the translators also influences the nature of translation. ${ }^{90}$ Roman translators did not select sacred texts for translation; whereas Jewish Scripture was the focus of many translational endeavours. The notable exception of Latin translation of religious texts is the Vulgate, a fourth-century CE translation of Greek and Hebrew Scriptures by Jerome. This Latin translation is much later than the examples discussed above and shows clear influence of Jewish translation practices through its relationship to the Christian church. Nevertheless, the Vulgate demonstrates that not all Latin approaches to translation were the same and that preferences changed over time, especially in consideration of the nature of the source text.

Importantly, the target text, once it has been rendered, begins to act independently from its source text. This new translation, embodied by the attribution of a new authorial name, is presented as its own literary work and so garners respect or derision often apart from the way that the original text continues to be viewed. In some cases, the new text might be found inferior to the perceived excellence of the source or the translation could be viewed as superior, surpassing the text from which it was birthed (so Pliny, Ep. 7.9.3-6; Gellius, NA 11.4.1-4). In such situations, judgment comes from literary elites who have access and the ability to read both works. Indeed, the pleasure afforded to one's literary equals through a good translation was thought to be a respected leisurely pursuit and the primary audience of such endeavours (cf. Cicero, Acad. 1.4-5). ${ }^{91}$ For the Jewish readers, the construction of a Greek text has important implications for the perception of the Hebrew. Honigman, for instance, claims that the blurring between editing and translating helps to prioritise the Greek text, as one only keeps the new, collated version and not the previous texts from which it was created. As a result, the Hebrew original can be forgotten now that the Greek text has been achieved..$^{92}$ Although I appreciate her perspective, I would disagree that the author of Aristeas advocates that view (cf. §177). Rather, the

88 What does it mean, then, that the Jewish authors felt compelled to follow the Hebrew text so closely so as to imbue the Greek with elements of the source language? Such a practice of developing 'poor' Greek was, in fact, the opposite intention of the classroom and would likely have been punished by the grammatikos. As a result, claiming a school setting for the origin of the LXX is still insufficient to determine exactly why the Greek translation developed as it did.

89 See also Philo, Mos. 2.40; Josephus, Ant. 12.101-109.

90 On the sacred nature, see Kelly (1979) 69. For the esteem of translated texts, see McElduff (2013) 6; Lianeri/Zajko (2008).

91 In contrast, the ridicule for a poor translation was also part of the risk of translation work. Cf. Gellius, NA 2.23.1-22.

92 Honigman (2003) 49. 
author of Aristeas depicts the Greek version as being functionally identical with the original Hebrew and so can be used in proxy for the Greek speakers in Alexandria. ${ }^{93}$ The creating of functional equivalence is markedly different from the practice of Latin authors, for whom the translated text with its new authorial stamp is intended to both supersede and displace (to some extent) the original Greek composition among Latin readers. ${ }^{94}$

\section{Conclusion}

In conclusion we find significant similarities and differences between Roman and Jewish depictions of literary translation. In particular, the importance of the source text, the direction of translation, and the intended purpose of the new work are key determiners of the nature of translation undertaken by the translator. A majority of the differences are a result of differences in power dynamics with Greek culture. The dominance of the Romans affords them the ability to take liberties with the text and to bring the wealth of Greek literary heritage into the Latin world. In contrast, Jewish translators did not translate Greek texts into Hebrew or Aramaic, presumably because in Egypt the Jews already had access to these texts. Rather, Jewish translators rendered their own ethnicity's works into Greek with high fidelity to the nature and structure of the original.

One of the key findings of this work is the recognition of the diversity of translation perspectives in antiquity, which I argue fall primarily along the lines of power. Engagement with another people group's literature and language engenders hierarchy and cultural negotiation; it is not a benign act. By contrasting Roman and Jewish practices, one can identify distinctive elements and demonstrate how individuals from diverse but interacting cultures can differ in the ways in which they engage in the scholarly practice of translation. Future studies, I would argue, need to engage

93 Cf. Wright (2015) 439. Cf. Philo, Mos. 2.40, which implies that comparison of the translated text with the original would yield the result of both being identical in meaning. Indeed, Philo resists seeing the Greek version as a translation, but describes it with the language of priests and prophets (oủx

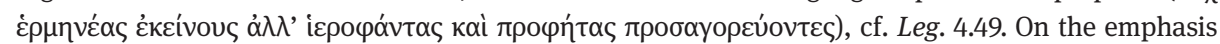
on the preservation of the text, see Veltri (2006) 36; Borchard (2012) esp. 12-15.

94 For the rhetorical claim of translational accuracy with regard to Scripture, but with clear authorial changes, see Josephus, Ant. 1.5, 10 -13 (for explicit mention of translation model); C.Ap. 1.54. Cf. Josephus' description of Manetho's history in similar terms (C.Ap. 1.228). The literal translation, moreover, is a constant reminder to the reader that this text was not originally composed in Greek, but is a translation. McElduff (2013) 9 claims that 'Comparing a translation with its source would be difficult, even if one were interested in doing so, and we never hear of a translator doing so'. Although this might be true for Latin authors (though, see Gellius, NA 7.2.1-3; 8.8 [the content is sadly lost]; 10.22.3), McElduff's statement is challenged by the narrative of Aristeas and the history of Septuagint revisions, for which we have ample evidence that later readers were regularly comparing the rendered text with its original and engaging in new translations that would be closer to the source. 
this idea when considering both translation acts and depictions of translations. In the case of Aristeas the presentation of translation in terms of scholarly language is a strategic move on behalf of the author in which he makes a statement regarding both the translated text and the people who made it. ${ }^{95}$

95 I would like to thank James K. Aitken and those who attended the 'Ancient Scholarship' conference at the University of Glasgow for their feedback and input. 
